\title{
Credit default swap spreads: market conditions, firm performance, and the impact of the 2007-2009 financial crisis
}

\author{
Xiaoqing $\mathrm{Fu}^{1} \cdot$ Matthew C. $\mathrm{Li}^{2} \cdot$ Philip Molyneux ${ }^{3}$
}

Received: 14 May 2019 / Accepted: 2 March 2020 / Published online: 12 March 2020

(c) The Author(s) 2020

\begin{abstract}
We employ a multi-factor analysis from both a firm-specific (microeconomic) and market-specific (macroeconomic) perspective to examine the determinants of credit default swap (CDS) spreads in the USA, the UK and Japan between 2005 and 2012. We investigate both aggregate (cross-country) and individual market data so that a comparative analysis can be performed. Our results reveal that (i) in general, Tobin's $\mathrm{Q}$, stock market returns, and the risk-free interest rate possess significant explanatory power for CDS spreads; (ii) the relationship identified is found to exist in all three markets with varying strength; (iii) despite the added information flow, the 2007-2009 financial crisis did not shorten the persistence (adjustment speed) of CDS spreads to variations in our explanatory variables; and (iv) degree of firm leverage appears to have a significant influence on CDS spreads. These results are robust to various model specifications. Synthesizing our overall results, we maintain that to reap the benefits of using CDSs as a risk management tool, greater attention should be devoted to supporting a stable market (economic and financial) environment. This paper contributes to elucidate how firm performance and macroeconomic conditions play a significant role in explaining CDS spreads.
\end{abstract}

$\bowtie \quad$ Matthew C. Li

matthew.li@rhul.ac.uk

Xiaoqing Fu

maggiefu@um.edu.mo

Philip Molyneux

p.molyneux@sharjah.ac.ae

1 Faculty of Business Administration, University of Macau, E22 Avenida da Universidade, Taipa, Macau, China

2 School of Business and Management, Royal Holloway University of London, Egham, Surrey TW20 0EX, UK

3 College of Business Administration, University of Sharjah, Sharjah, United Arab Emirates 
Keywords Credit default swap spread - Structural models · Firm performance · Macroeconomic conditions · Financial crisis

JEL Classification $\mathrm{G} 10 \cdot \mathrm{G} 15 \cdot \mathrm{G} 32$

\section{Introduction}

Credit default swaps (CDSs) were first introduced around 1994 by the investment bank JP Morgan and have grown substantially since. As of end-June 2016, the notional amount of outstanding CDS contracts stood at US $\$ 11.8$ trillion and the market value of CDS stood at US $\$ 342$ billion in gross terms and US $\$ 97$ billion in net terms. Although the notional amounts of CDS continued to decline from end-June 2016, owing to decreased activity between reporting dealers, by end-June 2018, total notional amounts still stood at $\$ 8$ trillion (BIS 2018). CDSs serve as a form of insurance against the occurrence of a borrower's default. A CDS contract entails the purchaser (protection buyer/lender of a loan) paying a premium to the issuer (an insurance company or a financial institution) against the default of the borrower. If no default occurs, the purchaser makes premium payments for the duration of the contract, while in the case of default, the issuer pays the CDS purchaser for the loss, and the contract closes. The premium that the purchaser pays in this contract is calculated as the CDS spread. Similar to other insurance products, the amount of default risk is priced in the spread. Any changes in factors that could impact the perceived level of risk, or in the case of a CDS contract, the probability of a borrower (reference entity) default, will be reflected in the CDS spread. Considering the significant use of CDSs as a risk management tool among financial markets and institutions since its development, a fuller understanding of CDS spread determinants will help to enhance the pricing and structuring of CDS contracts.

This paper uses a structural model setting to examine firm-specific and marketspecific determinants of CDs spreads. To facilitate a comparative study, we select the three largest CDS markets - the USA, the UK, and Japan. ${ }^{1}$ The paper examines the determinants of CDS spreads using two approaches. Firstly, we employ a multi-factor analysis from both firm-specific (microeconomic) and market-specific (macroeconomic) perspectives. Secondly, we investigate both aggregate and individual market data so that a comparative analysis can be performed. Our overall empirical results reveal that (i) Tobin's Q, stock market returns, and the risk-free interest rate possess significant explanatory power for CDS spreads; (ii) the relationship identified in (i) is found to exist in all three markets with varying strength; (iii) the 2007-2009 financial crisis did not altered the persistence of spreads (adjustment speed) of CDS spread to changes in our explanatory variables; and (iv) firm leverage appears to have a significant influence on CDS spread determinations.

\footnotetext{
1 Most of the extant literature focus on US data (Annaert et al. 2013; Baum and Wan 2010; Tang and Yan 2007; Doshi et al. 2013; Galil et al. 2014; Ericsson et al. 2009; Avramov et al. 2007; Bai and Wu 2016). The literature on non-US markets is more limited (Abid and Naifar 2006; Corò et al. 2013; Chiaramonte and Casu 2013; Blanco et al. 2005; Doshi et al. 2017; Monfort and Renne 2013).
} 
This paper advances the study of CDS determinants in four important ways. First, although influence of macroeconomic conditions has been tested in previous work such as Duffie et al. (2007), Tang and Yan (2006), and Baum and Wan (2010), under a single country setting, our empirical testing entails three individual CDS markets so that country-specific characteristics can be captured and compared. Second, similar to Stulz (2010), Di Cesare and Guazzarotti (2010), and Chiaramonte and Casu (2013), the potential impact of the 2007-2009 financial crisis on the CDS market is examined. Third, CDS spread movement dynamics are also inspected through a first-order autoregressive (1st-order Auto) process. Finally, firm leverage effect is included as a robustness check.

The remainder of this paper is organized as follows: Section 2 reviews the previous literature on CDS spreads. Section 3 presents a description of our research design which comprises model specification, variables used, and data. In Sect. 4, we analyse the empirical results. Section 5 discusses the robustness test, and Sect. 6 is the conclusion.

\section{Determinants of CDS spreads}

The literature on CDS spreads can be grouped according to the modelling approach used or explanatory variables employed. Here we discuss both groups.

\subsection{Structural versus reduced-form models}

Structural models closely relate to the option pricing model originally developed by Black and Scholes (1973) and Merton (1974). These models are constructed on the assumption that CDS spreads are driven by the degree of default risk of the reference entity. Hence, any factors that impact on the reference entity's probability of default will cause adjustments to its risk premium. This relationship between CDS spread and credit risk factors has been studied by a number of authors including: Annaert et al. (2013), Aunon-Nerin et al. (2002), Abid and Naifar (2006), Eichengreen et al. (2012), Longstaff et al. (2005), Blanco et al. (2005), Tang and Yan (2006), Chiaramonte and Casu (2013), Baum and Wan (2010), Ericsson et al. (2009), Avramov et al. (2007), Di Cesare and Guazzarotti (2010), Bai and Wu (2016), and Galil et al. (2014).

Reduced-form models, typically using an event study approach, focus on examining random shocks that influence CDS spreads. Whereas structural models assume a deterministic relationship between CDS spread and factors that could change firm values and their default probability, reduced-form models view default as determined by exogenous random shocks. Studies that use the reduced-form approach include Lando (1998), Jarrow et al. (1997), Hull and White (2001), Duffie and Lando (2001), Zhang et al. (2009), Doshi et al. (2013), Augustin and Tégongap (2016). Despite their simplicity, reduced-form models have been criticized for the lack of an economic rationale in explaining their results (Alexopoulou et al. 2009). As such, the majority of researches on the determinants of CDS spreads have focused on using structural models that employ firm- and market-specific factors to explain spreads 


\subsection{Explanatory variables investigated}

The key underlying assumption of the structural models is that any factors that alter a firm's value will directly or indirectly affect its ability to meet future debt repayments and hence its default probability. Since a reference entity's default risk is priced in the CDS spread, these factors should contain important information about the pricing of its spread vis-à-vis credit risk. Indeed, according to the structural models, CDS spread serves as an indicator of a firm's credit risk, and the market's ability to correctly price this risk is fundamental to the smooth functioning of both the CDS and debt markets. A substantial number of literatures use structural models to investigate the determinants of CDS spreads. One of the earliest studies by Collin-Dufresne et al. (2001) investigates monthly US bond data and finds that firm leverage and implied volatility together possess $25 \%$ explanatory power for CDS spread changes. Aunon-Nerin et al. (2002) examine both firm- and market-specific variables (such as asset volatility, stock price, leverage, credit ratings, and market capitalization) and find that taken together they explain up to $82 \%$ of CDS spreads. Similarly, Abid and Naifar (2006) include credit ratings, CDS contract maturity, stock volatility, risk-free interest rates and yield curves to investigate the spreads and find that their model explains $60 \%$ of the variation in European CDS pricing with credit ratings found to be the most influential factor. Using European reference entities, Corò et al. (2013) identify liquidity as a critical determinant of CDS price changes. Chiaramonte and Casu (2013) investigate bank CDS determinants. Using bank performance (ROE, ROA) and various balance sheet indicators (such as net loan/deposits, liquid assets/deposits, among others), they find that while balance sheet ratios vary strongly over time, liquidity variables appear to have the most significant impact on CDS pricing after the 2007-2009 crisis period. Focusing on US reference entities, Baum and Wan (2010) examine how macroeconomic uncertainty as measured by GDP growth, and various firm-specific variables (stock values, volatility and returns, ROE, dividend payout, and credit ratings) influence CDS spreads. They find that macroeconomic uncertainty is an important determinant and the effects of dividend payout and ROE differ greatly according to issuers' credit rating. Galil et al. (2014) again study the determinants of US CDS spreads using a similar array of both firm-specific and common market-specific variables, and they find that after controlling for firm-specific effects, market factors have greater explanatory power. Taking all this literature together, while some studies show that firm-specific factors are more important in explaining variations in CDS spreads, others suggest that market-specific (macroeconomic) factors may be just as important. With a clear objective of adding evidence to elucidate the study of CDS determinants, we perform further investigations in a cross-country setting using information from the three largest CDS markets.

\section{Data and research design}

\subsection{Data}

We collect data from Bloomberg and perform applicable calculations to generate the required variables. The full sample covers the period from March 2005 to December 
2012. While daily CDS spreads and stock market prices are available, GDP figures are announced quarterly. Firm-level data are mostly collected from financial statements such as balance sheets and income statements. However, the publication of these statements varies across countries. Both Japan and the USA provide us with the quarterly data that we require; however, because only semi-annually statements are available in the UK, we adopt the linear interpolation approach used in Collin-Dufresne et al. (2001), Tang and Yan (2007), and Ericsson et al. (2009), to obtain UK quarterly data. The initial sample includes all 5-year CDS spread data, but we omit any reference entities that either do not have data covering the entire sample period or have inactive CDS spread movements for four or more consecutive quarters. This leaves us with 444 single-name reference entities and a final sample of 14,208 quarterly observations in a balanced panel format.

\subsection{Model specification}

Our investigation of the explanatory power of both firm-specific and market-specific variables for CDS spreads is based on a structural modelling approach. We use a framework that is similar to Collin-Dufresne et al. (2001), Avramov et al. (2007), Ericsson et al. (2009), Baum and Wan (2010), Galil et al. (2014), and among others. We examine the explanatory power of six variables for CDS spread and detect their statistical significance on the proposed relationship through five different perspectives. First, we empirically test for the hypothesized relationship by examining the aggregate data of the three countries. Second, we study the relationship at the individual country level. Third, we test for the impact of the 2007-2009 financial crises on the relationship. Fourth, we analyse the speed of CDS spread adjustment to changes in the explanatory variables. Finally, we assess the existence of a firm leverage effect. Through the use of these six explanatory variables, we extend the recent models of Corò et al. (2013), and Galil et al. (2014). Furthermore, by re-testing the influence of leverage on spreads (as done in earlier work of Collin-Dufresne et al. 2001 and Aunon-Nerin et al. 2002), we offer a better understanding of its role in CDS spread formation and provide evidence of result robustness simultaneously.

Our first empirical model entails the use of Eq. (1) which primarily follows factors employed by Tang and Yan (2007), Acharya and Johnson (2007), and Pires et al. (2011):

$$
\begin{aligned}
\operatorname{CDS}_{i, t}^{n}= & \alpha_{0}+\alpha_{1} \mathrm{ROE}_{i, t}^{n}+\alpha_{2} \mathrm{TOBQ}_{i, t}^{n}+\alpha_{3} \mathrm{GDPQoQ}_{t}^{n}+\alpha_{4} \mathrm{SWP}_{t}^{n} \\
& +\alpha_{5} \mathrm{STKR}_{t}^{n}+\alpha_{6} \mathrm{STKV}_{t}^{n}+\gamma_{1} \text { Firm Fixed Effects }{ }_{i}^{n} \\
& +\gamma_{2} \operatorname{AR}(1)_{i}^{n}+\vartheta_{i, t}^{n}
\end{aligned}
$$

where $\operatorname{CDS}_{i, t}^{n}$ represents the CDS spread of reference entity $i$ at time $t$. The total number of reference entities is 444 , with 48 for the UK; 176 for Japan; 220 for the USA, whereas $n=1$ (UK); 2 (Japan); 3 (USA); and $1+2+3$ (aggregate). ${ }^{2}$ ROE and TOBQ are the two firm-specific variables indicative of the performance of firm $i$ at

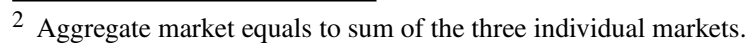


time $t$. GDPQoQ, SWP, STKR, and STKV are market-specific variables representing the economic/financial conditions of the particular market. $v$ is the idiosyncratic error term.

To take into account the cross-sectional and time-series dimensions nature of our dataset, a balanced panel data approach is adopted. We estimate Eq. (1) using firm fixed-effect least squares with cross-section seemingly unrelated regressions (SUR) robust standard error method to control for heteroscedasticity and autocorrelation. Cross-sectional dependence (CD) is a common problem in cross-country panels with various cross sections (firms), especially when countries and/or firms are somehow interconnected and spill-over effects can emerge. To test for CD in the model residuals, we apply: Breusch-Pagan Chi-square, Pearson LM Normal, and Pearson CD Normal tests. ${ }^{3}$ All three tests produce $p$ value of 0.000 ; hence, we reject the null hypothesis of cross-sectional dependence, and it suggests that correlations among residuals could be a concern in our model which could potentially bias our estimators. Considering these test results, we use the cross-section SUR approach to produce more efficient estimators. ${ }^{4}$ In Eq. (1), we also include a first-order autoregressive (AR(1)) term to facilitate the testing for the speed of CDS adjustments to changes in the explanatory variables. To fully utilize our dataset, based on the assumption that all three markets are homogenous, i.e. these three-market sample data can be considered as originated from a single zone, we firstly run regression on the aggregate sample. This assumption is then relaxed, and the three individual markets are separately tested for their unique country-specific characteristics. Another reason for performing regressions on the three national CDS markets independently is due to the fact that the existence of country-specific effect may be concealed if only aggregate data are examined. To identify these potential market differences, we continue to maintain the hypothesized relationship as stipulated in Eq. $(1)^{5}$ for the three individual markets, and indeed if market-specific characteristics exist, they can be observed through the number and magnitude of those statistically significant estimated coefficients among the three markets.

\subsection{Explanatory variables}

To investigate the hypothesized relationship specified in Eq. (1), we have CDS spread levels (CDS) as the dependent variable and six explanatory variables. Serving as explanatory variables, we have four market-specific factors which comprise two firmspecific performance measures (ROE, Tobin's Q); two economic indicators (GDP quarter-over-quarter growth, 5-year zero swap interest rate); and two stock market indicators (stock market return, stock market volatility). Additionally, to aid the inspection of CDS spread persistence, the model is supplemented by an $(\operatorname{AR}(1))$ term. The reasons for our choice of these explanatory variables are further explained below.

\footnotetext{
3 In the software-Eviews, these three tests are available for testing cross-sectional dependence. They are based on the null hypothesis of cross-sectional independence.

4 See Sarafidis and Wansbeek (2012) for details of the SUR approach.

5 The same reasoning applies to Eq. (2) presented later in the paper.
} 


\subsubsection{Firm-specific variables}

Following Baum and Wan (2010), Chiaramonte and Casu (2013), and Galil et al. (2014) our first firm-specific variable is the return on equity (ROE) ratio, which is computed by dividing a firm's net income by its total equity. ROE measures a firm's profitability in terms of the return to shareholders on their equity. Given its formation, a firm with a high ROE ratio signals strong financial performance, and hence, a lower probability of a default event will occur, and therefore a lower CDS spread should be observed; in other words, a negative relationship between CDS and ROE should transpire.

The second firm-specific performance indicator that we have chosen is Tobin's Q (TOBQ). Tobin's Q is measured as a ratio representing the sum of the market value of the firm's equity and book value of its debt to its total assets. TOBQ is frequently used to gauge the replacement cost of a firm's assets. The reference point of TOBQ is 1 , that is, the current value of a firm's assets exactly matches its replacement cost. Inasmuch, a TOBQ value greater than 1 suggests that the firm is performing well, whereas a value of smaller than 1 tells us otherwise. Based on this premise, we expect a negative relationship between CDS and TOBQ. Specifically, we maintain that when a firm is performing well as shown by a high TOBQ ratio, the probability of a credit default declines and the value of the CDS falls.

\subsubsection{Market-specific variables}

We use market-specific variables which represent macroeconomic conditions (e.g. Corò et al. 2013; Chiaramonte and Casu 2013; Baum and Wan 2010; Duffie et al. 2007; Abid and Naifar 2006; Korajczyk and Levy 2003; Fama and French 1989). In this paper, a country's market-specific effect on CDS spread is examined in two perspectives: general economic (GDP, risk-free interest rate) and financial (stock market return, stock market volatility) effects.

We capture the general economic condition of a country through two variables - GDP growth and the risk-free interest rates. As agreed in Tang and Yan (2006), fluctuations in GDP are important indicators of a country's economic conditions. More recently, studies (Darracq-Paries and De Santis 2015; Bleaney et al. 2016; De Santis 2016; Krishhnamurthy and Muir 2015; Mian et al. 2015; Bordalo et al. 2015; López-Salido et al. 2016) have found statistical effects of economic condition on the fluctuations in credit spreads. To measure GDP growth, we use quarter-over-quarter growth rate (GDPQoQ), whereas the risk-free interest rate is proxied by the 5-year zero swap rate (SWP). When an economy grows, a rising GDPQoQ emerges and business confidence expands together with greater business opportunities; this leads to improvements in firm profitability. Again, with rising profits, firms' abilities to make debt payments are boosted, and hence, a fall in default risk premium is anticipated and CDS spread falls. Therefore, a negative connection between CDS and GDPQoQ is expected.

The effect of risk-free interest rates has been studied by Longstaff and Schwartz (1995), Abid and Naifar (2006), Collin-Dufresne et al. (2001), Doshi et al. (2013), Ericsson et al. (2009), and Blanco et al. (2005). They show that the risk-free rate 
contains information about CDS spreads. As a proxy for the risk-free interest rate, we choose the 5-year zero swap rate (SWP) ${ }^{6}$ which determines the risk-adjusted drift of firm value-an increase in the risk-free rate reduces risk-adjusted default probabilities, and hence, CDS spread falls. We therefore expect a negative relationship between the risk-free rate and CDS spreads.

The findings of Abid and Naifar (2006), Galil et al. (2014), Collin-Dufresne et al. (2001), and Acharya and Johnson (2007) demonstrate that stock market returns and volatility are important indicators of changes in the business climate. We calculate stock market returns (STKR) ${ }^{7}$ by using the stock index closing price $(P)$ of the relevant stock exchange. ${ }^{8}$ Under a strong business environment, a higher stock market return signals that generally firms are performing well; therefore, the default risk associated with their debt payments will be lower. We expect a negative relationship between CDS and STKR, since as economic confidence rises, stock market return increases and CDS should fall.

Unlike Collin-Dufresne et al. (2001), Doshi et al. (2013), and Galil et al. (2014), where the CBOE Volatility Index (VIX) is used to represent stock market volatility, since our sample embraces three different country data, we compute our stock market volatility (STKV) through the use of a GARCH $(1,1)$ model $^{9}$ for the three individual markets. Our volatility measure is similar to that of Byrne and Davis (2005), and Driver et al. (2005). According to Merton (1974)'s structural model of default, ${ }^{10}$ corporate debt securities resemble those of a short put option on a firm's assets and a riskfree loan. Following the same vein of analysis, as stock market volatility increases, the related option values also increase, so asset volatility rises; this leads to a greater probability of default and results in a higher CDS spread. Alternatively, it is not difficult to see that a volatile stock market creates a higher degree of business uncertainties which will adversely affect the likelihood of firm default. Overall, we postulate a positive relationship between CDS and STKV because as business climate instability increases, stock market volatility increases, and a rise in CDS follows.

\subsubsection{Overall variable summary}

Table 1 displays the predicted signs of the six explanatory variables previously discussed.

Figure 1 graphically displays the relationships among our four market-specific variables in the three countries over time. From the three panels, we observe that stock market returns fluctuate more than stock market volatility, GDP growth and swap rate. Another noteworthy feature is the much-increased movements in these four

\footnotetext{
6 These are 5-year government CDS spreads, sometimes also called the LIBOR zero rates, which are closely associated with the opportunity cost of capital. Blanco et al. (2005) provide a clear discussion on the rationale for using these swap rates as risk-free rates.

$7 \mathrm{STKR}_{t}=\ln \left(\frac{P_{t}}{P_{t-1}}\right)$.

${ }^{8}$ FT100, Nikkei 225, and S\&P500 for the UK, Japan, and the USA, respectively.

9 We use a GARCH $(1,1)$ model that takes into account shocks from the prior period and the variance from the last period. More detailed descriptions of this model can be found in Li (2007).

10 For a detailed discussion of the model, see Sundaresan (2013).
} 
Table 1 Explanatory variables and predicted signs on estimated coefficients

\begin{tabular}{lll}
\hline Explanatory variable & Description & Dependent variable CDS \\
\hline ROE & Return on equity & - \\
TOBQ & Tobin's Q & - \\
GDPQoQ & GDP quarter-over-quarter growth rate & - \\
SWP & Swap rate & - \\
STKR & Stock market return & - \\
STKV & Stock market volatility & + \\
CRISIS & Crisis dummy variable & +
\end{tabular}

Firm performance indicators: $R O E$ net income/total equity, $T O B Q$ market value of firm equity + book value of debt/total assets; market-specific indicators: GDPQoQ GDP quarter-over-quarter growth rate in \%, SWP 5-year zero swap rate, $S T K R \ln \left(\frac{P_{t}}{P_{t-1}}\right)$, where $P$ is the stock index closing price, $S T K V$ stock market volatility generated by a GARCH $(1,1)$ model. CRISIS 2007Q3-2009Q2 $=1$, otherwise $=0$

explanatory variables after 2007 ; this observation reveals the possible impact of the 2007-2009 global financial crisis on our market-specific variables.

The formation of ROE and TOBQ entails firm accounting data such as net income, total income and total equity, and hence, a potential high degree of correlation may exist. Pair-wise correlations between these variables are reported in Table 2. These statistics show that the UK has the lowest value of 0.28 between ROE and TOBQ, while the USA produces the highest correlation value of 0.62 , which can be considered as not highly significant. For market-specific variables, again overall correlation statistics gives us little concern.

Table 3 outlines the descriptive statistics of all the variables used in our empirical analysis. We observe two noticeable features in our sample data. First, with the highest standard deviation of 338.56, the USA is the most volatile among the three CDS markets, followed by the UK and Japan. Second, in terms of the four market-specific factors, the stock market related variables yield the largest movements of $11.21 \%$ (Japan) for STKR and up to $4.34 \%$ (USA) for STKV. Of the two firm-specific indicators, ROE exhibits the largest fluctuation up to 68.69 basis points. When compared to the stock market variables, we are not entirely surprised to see greater volatility in the CDS spreads series. Our calculations of both stock market return and volatility are based on a market-wise stock index, whereas our CDS spreads volatility measures the fluctuations of our sample firms' CDS spreads; therefore, a greater movement is anticipated.

\section{Estimation results}

\subsection{Statistical relationship between CDS spread and explanatory variables for the aggregate market?}

Table 4 displays the estimation results of the aggregate sample. We find Eq. (1) explains $69.80 \%$ of CDS spreads, which suggests a good fit improving upon those in Galil et al. 
Panel A: UK

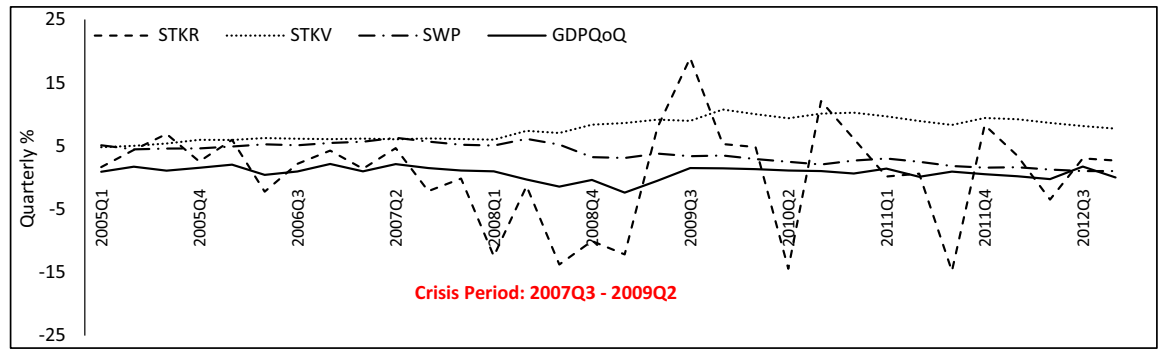

Panel B: Japan

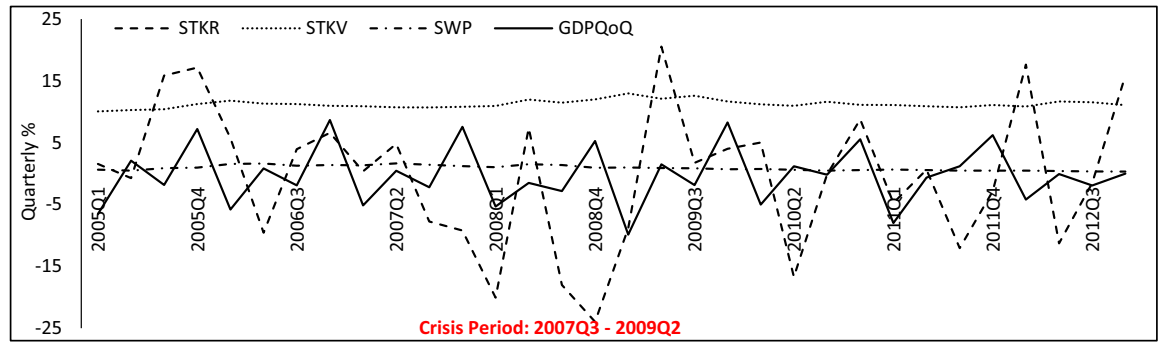

Panel C: US

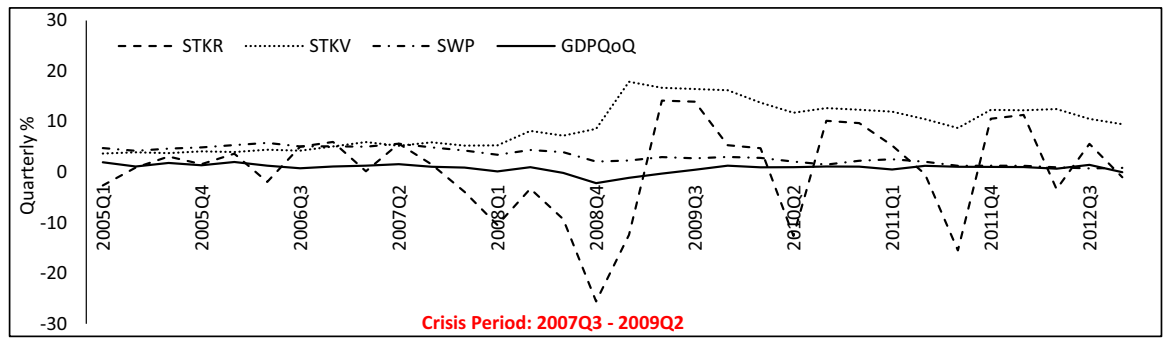

Fig. 1 UK, Japan, USA-market-specific variables movements

(2014) where only $16.23 \%$ explanatory power is found when firm-level stock return, volatility and leverage are investigated. All of the estimated coefficients have the predicted sign. Our findings differ from those of Ericsson et al. (2009), where creditspread changes are mostly captured by firm-specific variables. We find that together with the two firm-specific variables, ROE and TOBQ, our four market-specific variables, GDPQoQ, SWP, STKR, STKV, also demonstrate explanatory power for CDS. Specifically, this relationship is dominated by TOBQ, and the three market-specific variables (SWP, STKR, STKV) which are statistically significant at the $1 \%$ level. According to the overall results, at the aggregate level, we conclude that there exists an association between CDS and the market- and firm-specific variables. Particularly, our stock market return results are in agreement with Galil et al. (2014), where they also find that CDS spread changes in reaction to macroeconomic conditions as reflected in stock market price movements. 
Table 2 Cross-sectional time-series pair-wise correlations-sample period: 2005Q1-2012Q4
Firm performance indicators: $T O B Q$ Tobin's Q, ROE return on equity; market-specific indicators: GDPQoQ GDP quarter-over-quarter growth rate, SWP 5-year zero swap rate, $S T K R$ stock market returns, $S T K V$ stock market volatility

\begin{tabular}{|c|c|c|c|c|c|}
\hline & ROE & TOBQ & GDPQoQ & SWP & STKR \\
\hline \multicolumn{6}{|l|}{ Aggregate } \\
\hline TOBQ & 0.57 & & & & \\
\hline GDPQoQ & 0.03 & 0.08 & & & \\
\hline SWP & 0.12 & 0.31 & 0.16 & & \\
\hline STKR & 0.01 & 0.03 & 0.14 & 0.04 & \\
\hline STKV & -0.09 & -0.23 & -0.14 & -0.69 & 0.11 \\
\hline \multicolumn{6}{|l|}{ UK } \\
\hline TOBQ & 0.28 & & & & \\
\hline GDPQoQ & 0.01 & 0.09 & & & \\
\hline SWP & 0.01 & 0.13 & 0.20 & & \\
\hline STKR & -0.01 & 0.00 & 0.45 & -0.04 & \\
\hline STKV & -0.05 & -0.14 & -0.25 & -0.71 & 0.11 \\
\hline \multicolumn{6}{|l|}{ Japan } \\
\hline TOBQ & 0.45 & & & & \\
\hline GDPQoQ & -0.01 & 0.02 & & & \\
\hline SWP & 0.19 & 0.31 & -0.06 & & \\
\hline STKR & -0.06 & 0.00 & 0.08 & -0.08 & \\
\hline STKV & -0.16 & -0.14 & -0.10 & 0.11 & -0.08 \\
\hline \multicolumn{6}{|l|}{ USA } \\
\hline TOBQ & 0.62 & & & & \\
\hline GDPQoQ & 0.04 & 0.11 & & & \\
\hline SWP & 0.01 & 0.12 & 0.34 & & \\
\hline STKR & 0.00 & 0.03 & 0.49 & 0.05 & \\
\hline STKV & -0.04 & -0.14 & -0.38 & -0.70 & 0.22 \\
\hline
\end{tabular}

The magnitude of the TOBQ coefficient highlights its importance as a firm performance indicator in our overall estimated relationship. Indeed, the factor loading of TOBQ is 1.7 times larger than the factor loading of the SWP, and over 25 and 4.7 times larger than the factor loadings of STKR and STKV, respectively. Furthermore, this statistically significant relationship is shown to be mostly driven by variables that are market-value-based indicators instead of pure book-value-based indicator such as ROE. ${ }^{11}$ Perhaps unsurprisingly; this implies that investors place greater attention on market-based information when assessing and forecasting the default risk of CDS reference entities.

\footnotetext{
11 Although the formation of TOBQ also entails some book-value accounting data, unlike ROE, marketvalue data play an important role in its calculations.
} 
Table 3 Descriptive statistics of variables. Data source: Bloomberg

\begin{tabular}{|c|c|c|c|c|c|c|c|}
\hline & \multicolumn{3}{|c|}{ Firm-specific } & \multicolumn{4}{|c|}{ Market-specific } \\
\hline & CDS & ROE & TOBQ & GDPQoQ & SWP & STKR & STKV \\
\hline \multicolumn{8}{|c|}{ Panel A: aggregate } \\
\hline Mean & 133.01 & 11.45 & 1.37 & 0.39 & 2.38 & 0.20 & 9.80 \\
\hline Median & 62.65 & 6.71 & 1.20 & 0.98 & 1.62 & 1.54 & 10.81 \\
\hline Maximum & 6722.69 & 1448.34 & 8.29 & 8.67 & 6.28 & 20.54 & 17.89 \\
\hline Minimum & 2.67 & -309.91 & 0.55 & -9.88 & 0.31 & -25.56 & 3.70 \\
\hline $\mathrm{SD}$ & 268.40 & 51.02 & 0.55 & 3.12 & 1.74 & 9.77 & 3.37 \\
\hline Obs. & 14,208 & 14,208 & 14,208 & 14,208 & 14,208 & 14,208 & 14,208 \\
\hline \multicolumn{8}{|l|}{ Panel B: UK } \\
\hline Mean & 142.33 & 18.33 & 1.50 & 0.76 & 3.74 & 0.63 & 7.69 \\
\hline Median & 85.74 & 17.17 & 1.37 & 0.98 & 3.64 & 2.35 & 7.93 \\
\hline Maximum & 3123.03 & 387.97 & 4.97 & 2.14 & 6.28 & 18.91 & 10.75 \\
\hline Minimum & 3.67 & -271.02 & 0.80 & -2.38 & 1.03 & -14.79 & 4.80 \\
\hline $\mathrm{SD}$ & 204.23 & 42.82 & 0.55 & 1.00 & 1.59 & 7.79 & 1.72 \\
\hline Obs. & 1536 & 1536 & 1536 & 1536 & 1536 & 1536 & 1536 \\
\hline \multicolumn{8}{|c|}{ Panel C: Japan } \\
\hline Mean & 89.51 & 1.77 & 1.15 & -0.28 & 0.90 & -0.31 & 11.25 \\
\hline Median & 51.78 & 1.81 & 1.08 & -0.41 & 0.86 & 0.49 & 11.10 \\
\hline Maximum & 4531.62 & 15.79 & 4.00 & 8.67 & 1.65 & 20.54 & 12.96 \\
\hline Minimum & 2.67 & -33.71 & 0.55 & -9.88 & 0.31 & -23.97 & 10.05 \\
\hline $\mathrm{SD}$ & 154.39 & 3.77 & 0.29 & 4.75 & 0.41 & 11.21 & 0.62 \\
\hline Obs. & 5632 & 5632 & 5632 & 5632 & 5632 & 5632 & 5632 \\
\hline \multicolumn{8}{|c|}{ Panel D: USA } \\
\hline Mean & 165.79 & 17.70 & 1.52 & 0.84 & 3.27 & 0.51 & 9.10 \\
\hline Median & 68.69 & 14.57 & 1.36 & 1.05 & 3.01 & 1.56 & 8.67 \\
\hline Maximum & 6722.69 & 1448.34 & 8.29 & 2.02 & 5.79 & 14.17 & 17.89 \\
\hline Minimum & 4.83 & -309.91 & 0.59 & -2.18 & 0.75 & -25.56 & 3.70 \\
\hline SD & 338.56 & 68.69 & 0.65 & 0.84 & 1.58 & 8.85 & 4.34 \\
\hline Obs. & 7040 & 7040 & 7040 & 7040 & 7040 & 7040 & 7040 \\
\hline
\end{tabular}

Explanatory variable: $C D S$ 5-year credit default swap spreads. Firm performance indicators: $T O B Q$ Tobin's $\mathrm{Q}, R O E$ return on equity. Market-specific indicators: $G D P Q o Q$ GDP quarter-over-quarter growth rate, $S W P$ 5-year zero swap rate, STKR stock market returns, STKV stock market volatility

\subsection{Statistical relationship between CDS spread and explanatory variables for the three individual countries?}

To assess country difference in our proposed relationship, we run individual regressions for the three countries' CDS spreads. Table 5 presents the results that address our second question. Again, we see all estimated coefficients have the predicted sign. For 
Table 4 Estimation results for Eq. (1): explanatory power of firm performance and market conditions for CDS spreads at the aggregate market level

\begin{tabular}{|c|c|c|c|c|c|c|}
\hline \multirow[t]{3}{*}{ Intercept } & \multicolumn{6}{|c|}{ Explanatory variables } \\
\hline & \multicolumn{2}{|c|}{ Firm-specific } & \multicolumn{4}{|c|}{ Market-specific } \\
\hline & ROE & TOBQ & GDPQoQ & SWP & STKR & STKV \\
\hline $175.343 * * *$ & $-0.287 *$ & $-53.362 * * *$ & $-1.871^{*}$ & $-31.695 * * *$ & $-2.126 * * *$ & $11.461 * * *$ \\
\hline (3.714) & $(-1.663)$ & $(-4.107)$ & $(-1.776)$ & $(-3.083)$ & $(-4.131)$ & $(3.676)$ \\
\hline 1st-order auto & $0.666^{* * * *}$ & $(8.633)$ & Adj. $R^{2}$ & 0.698 & & \\
\hline $\begin{array}{l}\text { No. of } \\
\text { reference } \\
\text { entities }\end{array}$ & 444 & & No. of obs. & 13,764 & & \\
\hline
\end{tabular}

Estimation method: fixed-effect panel least squares with cross-section SUR standard errors and covariance. Associated $t$-ratios in parentheses

$* * *, * *, *$ Statistically significant levels of $1 \%, 5 \%$ and $10 \%$, respectively. Significant statistics are in bold. Sample period: 2005Q1-2012Q4

the firm-specific effect, the UK's and to a lesser extent the Japanese ROE contain information about CDS. In terms of the market-specific effect, both the Japanese and the US results highlight the statistical significance of all four market-specific variables. Among the three countries, it is shown that the US market gives us the best fitting model with the highest adjusted $R^{2}$ value of $73.30 \%$. With an explanatory power of up to $56.20 \%$, Japan is the next country that contains rather strong market-specific effect. Although the UK produces an adjusted $R^{2}$ value of $58.50 \%$, with only two (SWP, STKR) of our four market-specific variables being statistically significant, it becomes the weakest case of estimated coefficient significance. While mostly driven by marketspecific effects, our overall result suggests a statistical relationship between CDS and our explanatory variables in the three individual countries. However, the strength of this relationship varies according to the three countries with the US leading, followed by Japan and then the UK. Nevertheless, all three countries share a common feature-SWP and STKR consistently possess information about CDS. However, these country-specific results also maintain their own unique characteristics. While in the UK, ROE adds power to the estimated relationship, STKV helps to further explain CDS in Japan, whereas all market-specific factors play an important role in CDS in the USA.

\subsection{Impact of the 2007-2009 financial crisis}

During the 2007-2009 global financial crisis various commentators suggested that due to the nature of CDS contracts which allowed arrangements mirror re-insurance policies, financial institutions' involvement in CDS contracts led to a domino effect that deepened the crisis. Since the 2007-2009 crisis, interest in examining the CDS markets has intensified and a substantial body of work has evolved (for example, Eichengreen et al. 2012; Di Cesare and Guazzarotti 2010; Chiaramonte and Casu 2013; Kress 2011; 


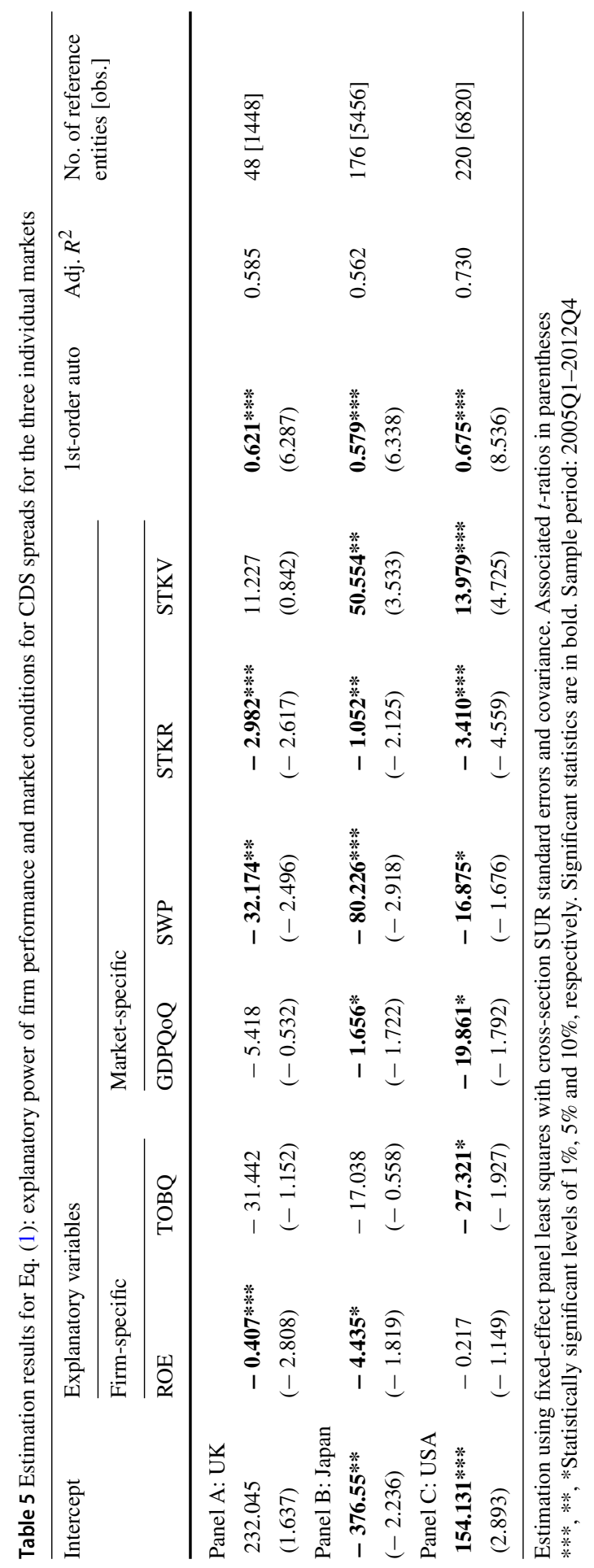


Stulz 2010; Dickinson 2008). To examine the financial crisis effect, a dummy variable CRISIS is introduced into our estimation of Eq. (2).

$$
\begin{aligned}
\operatorname{CDS}_{i, t}^{n}= & \beta_{0}+\beta_{1} \mathrm{ROE}_{i, t}^{n}+\beta_{2} \mathrm{TOBQ}_{i, t}^{n}+\beta_{3} \mathrm{GDPQoQ}_{t}^{n}+\beta_{4} \mathrm{SWP}_{t}^{n} \\
& +\beta_{5} \mathrm{STKR}_{t}^{n}+\beta_{6} \mathrm{STKV}_{t}^{n}+\beta_{7} \mathrm{CRISIS} \\
& +\gamma_{1} \text { Firm Fixed Effects }{ }_{i}^{n}+\gamma_{2} \mathrm{AR}(1)_{i}^{n}+\varepsilon_{i, t}^{n}
\end{aligned}
$$

Equation (2) incorporates all the explanatory variables of Eq. (1) with the addition of CRISIS. This dummy variable carries a value of " 1 " for the period from 2007Q3 to 2009Q2, and "0" otherwise. Owing to the relatively limited sample size of the UK and to minimize potential small sample bias, we do not divide the sample into two distinct periods: pre- and post-crisis, instead, as the preferred approach we directly integrating this crisis dummy variable into our equation. We expect that due to increased firm and market uncertainties over the crisis period, CDS will increase to reflect the heightened probability of firm default, and hence, a positive relationship between our dependent and this explanatory variable should prevail (see Table 1).

Table 6 presents the results and shows that CRISIS plays a part in the estimation of Eq. (2). When a crisis dummy is included in our estimation, its coefficient is highly statistically significant at the $1 \%$ critical level in all cases but one. Japan is the only case that lacks a significant crisis effect. When compared to the results presented in Tables 4 and 5, we now show that for the UK and Japan, though reacting to the crisis dummy differently, the magnitude of the other significant coefficients remains relatively stable. Although we demonstrate a crisis effect in the US sample which is in agreement with Corò et al. (2013), and Galil et al. (2014), the inclusion of the crisis dummy into the US regression has somehow changed the overall CDS relationship with a reduction in the number of statistically significant coefficients from five to four. In this particular case, we suspect that the crisis dummy has somehow weakened or obscured the CDS correlation with the market variable GDPQoQ, but not to a degree that substantially changes the overall hypothesized association.

\subsection{CDS spread speed of adjustment to changes in the explanatory variables}

It has been documented that financial data are frequently subject to the effect of persistence (see for example, Arize et al. 1999; Engle and Patton 2001; Li 2007; Ofek and Richardson 2003). Although most of these studies focus on volatility persistence, the evidence on price/return persistence provides us with support to investigate CDS spread pricing persistence in our model. Furthermore, this model specification helps to reflect market reality. In order to assess the speed of adjustment of CDS to the explanatory variables, we compare our results reported in Tables 4, 5 and 6 (and also later in Table 8). An evaluation between these tables reveals that the first-order autoregressive term plays an essential role in CDS with an average coefficient value of 0.6. Based on this observation, we maintain that CDS follows a slow adjustment path with close to $60 \%$ of past values of CDS spreads still explaining contemporary spreads. In other words, adjustments in CDS spreads cannot be fully explained by changes in market- 


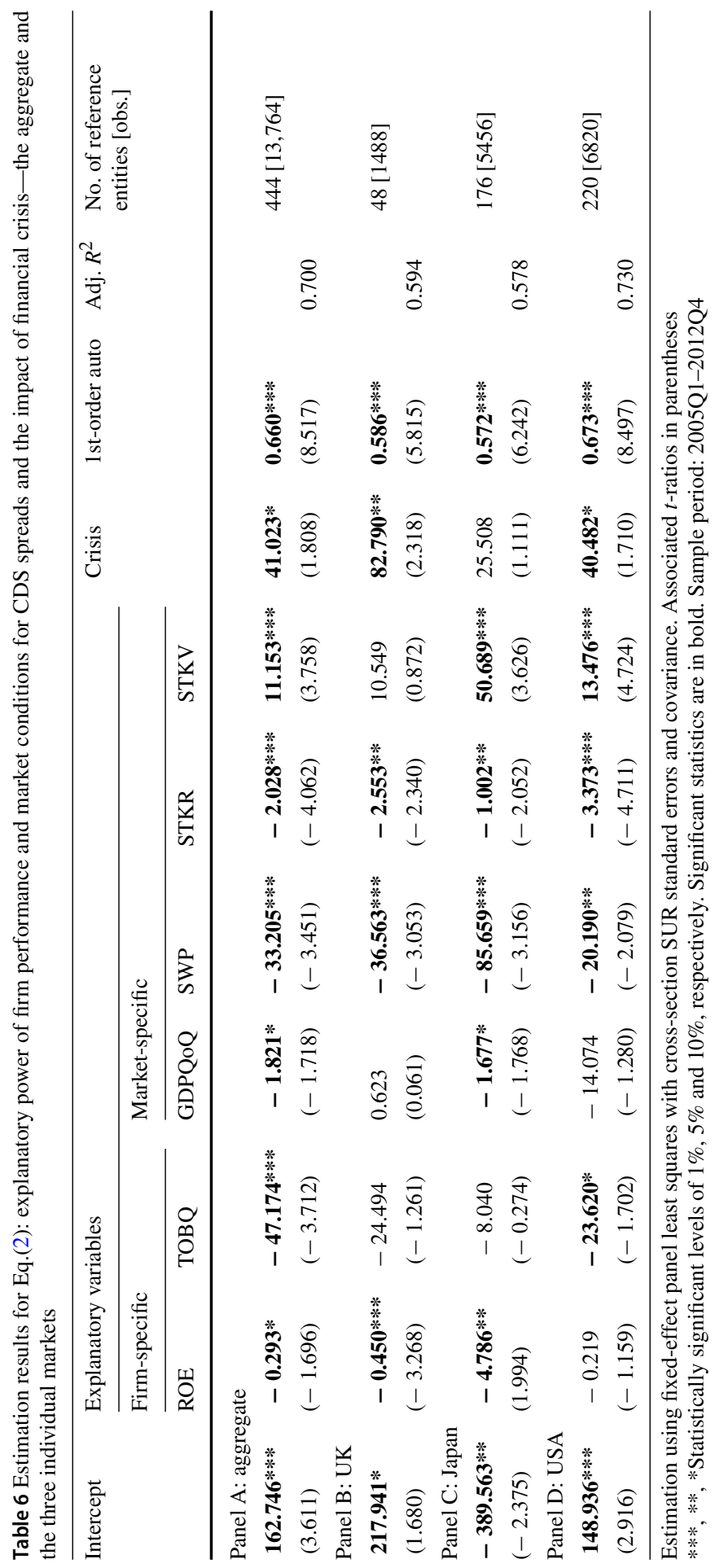


and firm-specific condition instantaneously and fully. ${ }^{12}$ Upon inspection of the AR(1) term in the crisis dummy regressions of Eq. (2), our results show that CDS persistence continues in all cases; namely, this finding indicates that current level of CDS spread is still affected by previous levels, as such we believe that the pricing memory process is not shortened during the 2007-2009 financial crisis. This observation differs from our initial expectation. Considering the intensive media coverage of financial news on firm performance, GDP movements, and stock market reactions during the crisis period, one would anticipate that it would substantially improve our independent variables' roles in enhancing the pricing kernel of CDS spreads, but this has not been shown in our sample countries.

\section{Robustness check}

In this section, we examine the strength of the hypothesized relationship under a different model setting. The main goal of this paper is to test for the explanatory power of those variables that affect the probability of firm default, and hence, the CDS spread. Although the reference entities that are chosen for this study possess similar credit ratings, ${ }^{13}$ the amount of firm leverage varies among our sample firms.

\subsection{Firm leverage sensitivity}

The effect of firm leverage ${ }^{14}$ on credit spreads has been previously studied by CollinDufresne et al. (2001), Galil et al. (2014), Ericsson et al. (2009), and Corò et al. (2013). Unlike the latter two that directly incorporate leverage as an explanatory variable in their estimations, we follow the work of Collin-Dufresne et al. (2001) by assigning leverage groups to the reference entities. We first calculate the average leverage for the aggregate market and the three individual markets, then each reference entity is assigned to a leverage group ("low" if below average leverage, "high" if above). ${ }^{15}$ Table 7 displays the distribution of "low"- and "high"-leverage groups in our reassigned samples. It can be seen that in general a higher proportion of reference entities belong to the "low"-leverage group than "high", except for Japan where the two are close to each other.

Equation (1) is re-estimated according to the re-sampled dataset. For the aggregate sample, when compared with results presented in Table 4, Panel A of Table 8 highlights that for low-leverage firms, there is little effect. However, for high-leverage firms, the information content of GDPQoQ and SWP no longer exists, and the two estimated coefficients of STKR and STKV are more than double in magnitude. The three individual countries' results are also presented in Table 8 and are compared to

\footnotetext{
12 Although the identification of duration of this persistence is not a trivial exercise, it is beyond the aims and scope of the existent paper.

13 Moody Credit Ratings for reference agencies are: UK: Aaa; Japan: Aaa to Aa1; USA: Aaa.

14 Firm leverage is defined as: $\frac{\text { Book value of debt }}{\text { Market value of equity + Book value of debt }}$.

15 Unlike Collin-Dufresne et al. (2001), we do not further break down the groupings into quintiles solely due to the relatively small UK sample size.
} 
Table 7 Distribution of "low"and "high"-leverage groups

\begin{tabular}{|c|c|c|c|c|c|}
\hline & \multicolumn{2}{|l|}{ Low } & \multicolumn{2}{|l|}{ High } & \multirow[t]{2}{*}{ Total number } \\
\hline & Number & $\%$ & Number & $\%$ & \\
\hline Aggregate & 345 & 78 & 99 & 22 & 444 \\
\hline UK & 37 & 77 & 11 & 23 & 48 \\
\hline Japan & 95 & 54 & 81 & 46 & 176 \\
\hline USA & 183 & 83 & 37 & 17 & 220 \\
\hline
\end{tabular}

those in Table 5. In the UK, the findings (Table 8, Panel B) show limited change in the results for low-leverage firms, whereas for high-leverage firms, firm-specific variables have no explanatory power for CDS, while the two market-specific variables (SWP, STKR) increase in size. The Japanese results (Table 8, Panel C) depict a substantial TOBQ coefficient $(-183.163)$ among low-leverage firms, and the magnitude of the statistically significant market-specific variables has also been increased. For Japanese firms in the high-leverage group, we obtain a similar number of statistically significant coefficients though their values have fallen in size by about $50 \%$. For the USA (Table 8, Panel D), for low-leverage firms, the influence of our independent variables on CDS spreads persists, but for highly leveraged firms only the two stock market variables remain statistically significant. Overall our findings generally concur with those of Collin-Dufresne et al. (2001) on the US CDS market.

In summary, when we re-estimate Eq. (1) by incorporating the degree of firm leverage, there appears to be only a moderate effect for firms with low leverage. Our results for highly leveraged firms confirm the importance of market-specific variables in explaining CDS. These observations indicate the case of a leverage effect in our sample. Nevertheless, our previous estimation findings are not altered by this effect substantively, and hence robustness is supported.

\section{Conclusions}

This paper examines the explanatory power of both firm- and market-specific variables on CDS spreads. We analyse a panel dataset covering 444 reference entities from the three largest CDS markets over the period 2005Q1-2012Q4. Based on a structural modelling approach, we test variables that could affect the default risk probability of a reference entity and hence CDS spreads. Our empirical results reveal that marketspecific variables possess significant explanatory power for CDS. Stock market return, stock market volatility and the risk-free interest rate appear to contain more information about CDS spread than the two firm performance indicators ROE and TOBQ. Our results agree with Collin-Dufresne et al. (2001) where market-based factors are found empirically to be more important than firm-specific variables in driving CDS spreads.

Overall our results provide answers to five key questions. First, at the aggregate cross-country level, there exists a statistical relationship between CDS spread and our firm- and market-specific variables with the latter having a more pronounced effect. Second, at the individual country level this relationship continues with market factors 


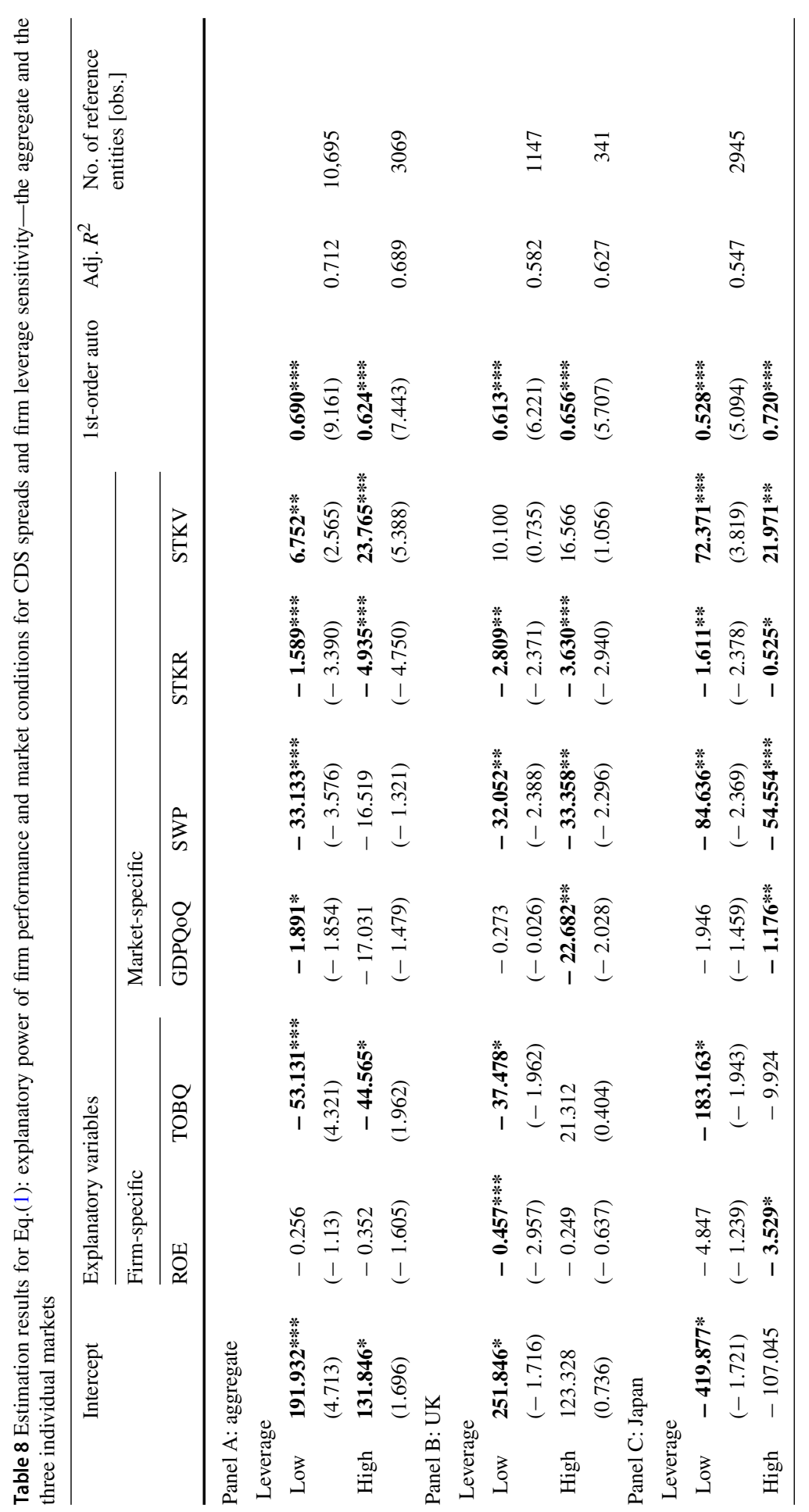




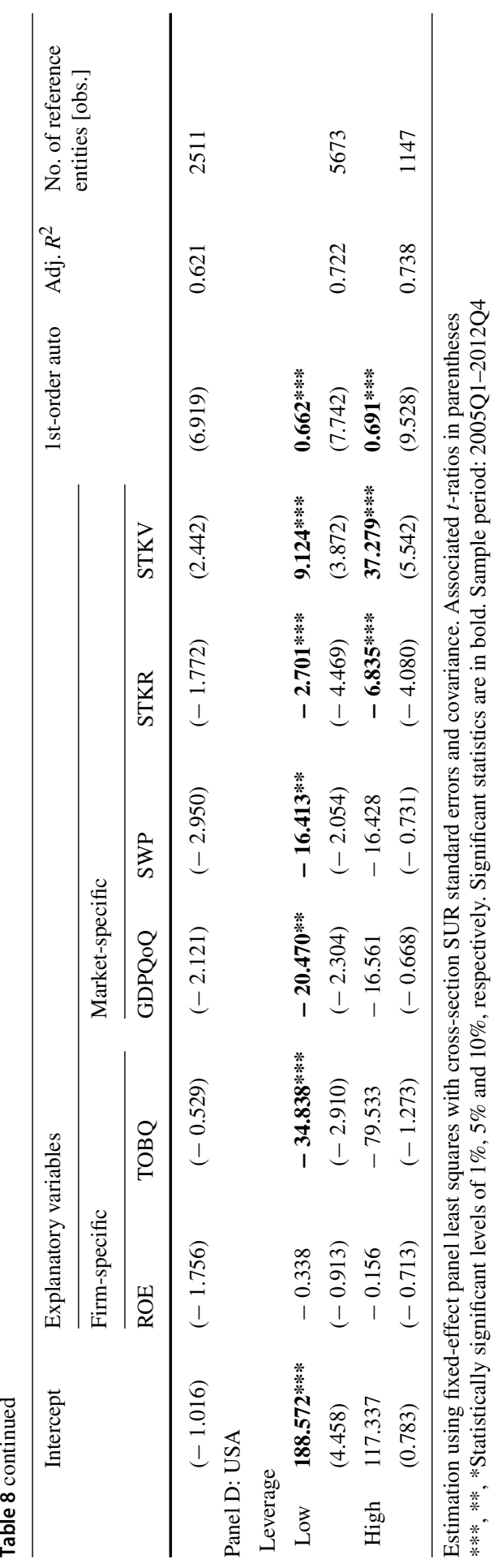


having a larger impact in the USA, followed by Japan and the UK. Third, Japan is the only case where we fail to observe a financial crisis effect. Fourth, CDS follows a slow path of adjustment with past values continuing to play an important role. Finally, the robustness of our results is supported by the negligible effect of leverage particularly for low-leveraged firms.

Synthesizing these results, we conclude that to reap the benefits of using CDSs as a risk management tool, greater attention should be devoted to supporting a stable market environment. This paper highlights the importance of market-specific factors such as risk-free rate, stock market return, and stock market volatility in explaining CDS spreads which is consistent with what is predicted by the model of Merton (1974). ${ }^{16}$ Having said this, our model settings capture at most $73 \%$ of the variation in CDS spreads, so some fundamental determinants of CDS spread remain to be discovered. Our paper suggests that further research should seek to explore other potential firmand market-specific variables that could help fully explain variations in CDS spreads. Our findings provide a contribution that should be of interest to market participants as well as regulatory agencies who wish to have a greater understanding of the behaviour of CDS markets.

Acknowledgements We thank the participants of the WEAI 2017 International Conference in Santiago for their valuable suggestions on an earlier version of this paper. We are also grateful for funding from the University of Macau [Grant Reference No.: MYRG008 (Y1-L1)]. All errors of course rest with the authors.

\section{Compliance with ethical standards}

Conflict of interest The authors declare that they have no conflict of interest.

Ethical approval This article does not contain any studies with human participants performed by any of the authors.

Open Access This article is licensed under a Creative Commons Attribution 4.0 International License, which permits use, sharing, adaptation, distribution and reproduction in any medium or format, as long as you give appropriate credit to the original author(s) and the source, provide a link to the Creative Commons licence, and indicate if changes were made. The images or other third party material in this article are included in the article's Creative Commons licence, unless indicated otherwise in a credit line to the material. If material is not included in the article's Creative Commons licence and your intended use is not permitted by statutory regulation or exceeds the permitted use, you will need to obtain permission directly from the copyright holder. To view a copy of this licence, visit http://creativecommons.org/licenses/by/4.0/.

\section{References}

Abid F, Naifar N (2006) The determinants of credit default swap rates: an explanatory study. Int J Theor Appl Finance 9:23-42

Acharya V, Johnson T (2007) Insider trading in credit derivatives. J Finance Econ 84:110-141

Alexopoulou I, Andersson M, Georgescu O (2009) An empirical study on the decoupling movements between corporate bond and CDS spreads. European Central Bank (EBC) working paper no. 1085, European Central Bank (EBC), Frankfurt. SSRN: https://ssrn.com/abstract=1456878

$\overline{16}$ The ability of using structural variables to explain CDS spreads. 
Annaert J, De Ceuster M, Van Roy M, Vespro C (2013) What determines euro area bank CDS spreads? J Int Money Finance 32:444-461

Arize A, Malindretos J, Shwiff S (1999) Structural breaks, cointegration, and speed of adjustment Evidence from 12 LDCs money demand. Int Rev Econ Finance 8:399-420

Augustin P, Tégongap R (2016) Real economic shocks and sovereign credit risk. J Finance Quant Anal 51:541-587

Aunon-Nerin D, Cossin D, Hricko T, Huang Z (2002) Exploring for the determinants of credit risk in credit default swap transaction data: is fixed-income markets' information sufficient to evaluate credit risk? FAME research paper no. 65

Avramov D, Jostova G, Philipov A (2007) Understanding changes in corporate credit spreads. Financ Anal J 63:90-105

Bai J, Wu L (2016) Anchoring corporate credit swap spreads to firm fundamentals. J Finance Quant Anal 5(5):1521-1543

Bank for International Settlements (2018) OTC derivatives statistics at end-June 2018

Baum C, Wan C (2010) Macroeconomic uncertainty and credit default swap spreads. Appl Financ Econ 20:1163-1171

Black F, Scholes M (1973) The pricing of options and corporate liabilities. J Polit Econ 81:637-654

Blanco R, Brennan S, Marsh IW (2005) An empirical analysis of the dynamic relation between investmentgrade bonds and credit default swaps. J Finance 60:2255-2281

Bleaney M, Mizen P, Veleanu V (2016) Bond spreads and economic activity in eight European economies. Econ J 126(598):2257-2291

Bordalo P, Gennaioli N, Shleifer A (2015) Diagnostic expectations and credit cycles. Harvard University working paper

Byrne JP, Davis EP (2005) Investment and uncertainty in the G7. Rev World Econ 141(1):1-32

Chiaramonte L, Casu B (2013) The determinants of bank CDS spreads: evidence from the financial crisis. Eur J Finance 19:861-887

Collin-Dufresne P, Goldstein RS, Martin JS (2001) The determinants of credit spread changes. J Finance 56:2177-2207

Corò F, Dufour A, Varotto S (2013) Credit and liquidity components of corporate CDS spreads. J Bank Finance 37:5511-5525

Darracq-Paries M, De Santis RA (2015) A non-standard monetary policy shock: the ECB's 3-year LTROs and the shift in credit supply. J Int Money Finance 54:1-34

De Santis RA (2016) Credit spreads, economic activity and fragmentation. European Central Bank. Working paper series no. 1930

Di Cesare A, Guazzarotti G (2010) An analysis of the determinants of credit default swap spread changes before and during the subprime financial turmoil. Bank of Italy Temi di Discussione. Working paper no. 749

Dickinson E (2008) Credit default swaps: so dear to us, so dangerous. Fordham University, School of Law, New York. https://doi.org/10.2139/ssrn.1315535

Doshi H, Ericsson J, Jacobs K, Turnbull S (2013) Pricing credit default swaps with observable covariates. Rev Financ Stud 26:2049-2094

Doshi H, Jacobs K, Zurita C (2017) Economic and financial determinants of credit risk premiums in the sovereign CDS market. Rev Asset Pricing Stud 7:43-80

Driver C, Temple P, Urga G (2005) Profitability, capacity, and uncertainty: a model of UK manufacturing investment. Oxf Econ Pap 57:120-141

Duffie D, Lando D (2001) Term structures of credit spreads with incomplete accounting information. Econometrica 69:633-664

Duffie D, Saita L, Wang K (2007) Multi-period corporate default prediction with stochastic covariates. J Financ Econ 83:635-666

Eichengreen B, Mody A, Nedeljkovic M, Sarno L (2012) How the subprime crisis went global: evidence from bank credit default swap spreads. J Int Money Finan 31:1299-1318

Engle RF, Patton AJ (2001) What good is a volatility model? Quant Finance 1:237-245

Ericsson J, Jacobs K, Oviedo R (2009) The determinants of credit default swap premia. J Financ Quant Anal 44:109-132

Fama EF, French KR (1989) Business conditions and expected returns on stocks and bonds. J Financ Econ 25:23-49 
Galil K, Shapir OM, Amiram D, Ben-Zion U (2014) The determinants of CDS spreads. J Bank Finance 41:271-282

Hull J, White A (2001) Valuing credit default swap II: modeling default correlations. J Deriv 8:12-22

Jarrow R, Lando D, Turnbull SM (1997) A Markov model for the term structure of credit spreads. Rev Financ Stud 10:481-523

Korajczyk RA, Levy A (2003) Capital structure choice: macroeconomic conditions and financial constraints. J Financ Econ 68:75-109

Kress JC (2011) Credit default swap clearinghouses and system risk: why centralized counterparties must have access to central bank liquidity? Harv J Legis 48:49-93

Krishhnamurthy A, Muir T (2015) Credit spreads and the severity of financial crises. Stanford University working paper

Lando D (1998) On Cox processes and credit risky securities. Rev Deriv Res 2:99-120

Li MC (2007) Wealth, volume and stock market volatility: case of Hong Kong (1993-2001). Appl Econ 39:1937-1953

Longstaff FA, Schwartz E (1995) A simple approach to valuing risky fixed and floating rate debt. J Finance 50:789-819

Longstaff FA, Mithal S, Neis E (2005) Corporate yield spreads: default risk or liquidity? New evidence from the credit default swap market. J Finance 60:2212-2253

López-Salido D, Stein JC, Zakrajšek E (2016) Credit-market sentiment and the business cycle. NBER working paper series no. 21879

Merton RC (1974) On the pricing of corporate debt: the risk structure of interest rates. J Finance 29:449-470

Mian AR, Sufi A, Verner E (2015) Household debt and business cycles worldwide. NBER working paper series no. 21581

Monfort A, Renne JP (2013) Decomposing Euro-Area sovereign spreads: credit and liquidity risks. Rev Finance 18:2103-2151

Ofek E, Richardson M (2003) Dotcom mania: the rise and fall of internet stock prices. J Finance 58:1113-1137

Pires P, Pereira JP, Martins LF (2011) The complete picture of credit default swap spreads—a quantile regression approach. https://doi.org/10.2139/ssrn.1125265

Sarafidis V, Wansbeek T (2012) Cross-sectional dependence in panel data analysis. Econom Rev 5:483-531. https://doi.org/10.1080/07474938.2011.611458

Stulz RM (2010) Credit default swaps and the credit crisis. J Econ Perspect 24:73-92

Sundaresan S (2013) A review of Merton's model of the firm's capital structure with its wide applications. Annu Rev Fin Econ 5:21-41

Tang DY, Yan H (2006) Macroeconomic conditions, firm characteristics, and credit spreads. J Financ Serv Res 29:177-201

Tang DY, Yan H (2007) Liquidity and credit default swap spread. SSRN: http://ssrn.com/abstract=891263 or https://doi.org/10.2139/ssrn.891263

Zhang B, Zhou H, Zhu H (2009) Explaining credit default swap spreads with equity volatility and jump risks of individual firms. Rev Financ Stud 22:5099-5131

Publisher's Note Springer Nature remains neutral with regard to jurisdictional claims in published maps and institutional affiliations. 